\title{
An infant who survived abortion and neonatal intensive care
}

\author{
P. CLARKE \\ Neonatal Intensive Care Unit, Hope Hospital, Salford, M6 8HD, UK \\ J. SMITH \\ Division of Neonatology, Tygerberg Children's Hospital, University of Stellenbosch, South Africa; \\ T. KELLY \\ Department of Obstetrics \& Gynaecology, Hope Hospital, Salford, M6 8HD, UK \\ M. J ROBINSON \\ Neonatal Intensive Care Unit, Hope Hospital, Salford, M6 8HD, UK
}

\section{Introduction}

Termination of pregnancy is a common procedure worldwide. In the UK, termination is legal until the 24 th week of pregnancy, and allowed throughout gestation in certain circumstances. Some infants aborted at the margins of viability (22 - 24 weeks' gestation) show signs of life at delivery. We report an infant who survived abortion at approximately 23 weeks' gestation and who survives long-term following many months of neonatal intensive care.

\section{Case report}

A 24-week gestation male infant was born alive in November 2002, several days after repeated attempts at medical termination of pregnancy. His mother was a 24-year old unmarried Caucasian with a 19-month old infant. She had presumed that monthly light bleeds were menstrual loss and only realised that she was pregnant in later gestation. An ultrasound scan estimated the gestation as 22 weeks +3 days. The pregnancy was unplanned and she opted for abortion because she felt unable to cope with a further child. She was admitted to a private abortion clinic on a Thursday at $23+1$ weeks' gestation. Following removal of $200 \mathrm{ml}$ of amniotic fluid, she underwent intra-amniotic injection of $80 \mathrm{~g}$ of urea. An intravenous oxytocin infusion continued over a 36-hour period. On Friday she was given a course of $5 \times 1 \mathrm{mg}$ gemeprost (a prostaglandin E1 analogue) pessaries. On Saturday she was given misoprostol (also a prostaglandin E1 analogue) $800 \mathrm{mg}$ vaginally, then $1.6 \mathrm{mg}$ orally over 12 hours. On Sunday following an ultrasound scan she was informed that the fetus was dead. Because labour had not been induced she was discharged home on antibiotics, with readmission scheduled for 4 days later.

During the 3-hour train journey home she felt fetal movements for the first time, and changed her mind about the abortion. That afternoon she developed abdominal pains and was admitted to hospital in early labour. She was counselled about the poor prognosis for her infant, but requested that resuscitation be attempted. She received dexamethasone and nifedipine. Four days later at $24+1$ weeks' gestation her son was delivered as a vaginal breech weighing $690 \mathrm{~g}$. The infant cried at birth and was vigorous. He was intubated, given surfactant and admitted to the neonatal intensive care unit. His postnatal course was stormy, typical of those surviving delivery at the margins of viability. Ventilated for 53 days, including 21 days of high frequency oscillation, he required inotropic support, indomethacin for a patent ductus arteriosus, and thromboplastin plasminogen activator for a large intracardiac thrombus. Lifethreatening infections included Serratia marcescens and Candida albicans septicaemias, and severe renal candidiasis. Severe chronic lung disease was managed with dexamethasone, nasal continuous positive airways pressure until aged 5 months, and supplementary oxygen until 6 months. Bilateral inguinal hernias required surgery.

Serial cranial ultrasound scans were normal. He eventually went home at 7 months, where he was a demanding infant with feeding problems and a very irregular sleeping habit. During intensive care 
his mother had frequently been informed that survival was unlikely, and this has contributed to significant bonding difficulties. Maternal guilt surrounding his premature birth and its associated sequelae was compounded by her child's on-going respiratory problems and several further hospital admissions. At 10 months corrected age he had mild motor developmental delay, though was making progress.

\section{Discussion}

Against all odds, this infant survived repeated abortion attempts and premature delivery. The case illustrates a paradox: the abortion was successful because the medical treatment (eventually) terminated the pregnancy; at the same time it was a failure because the fetus was expelled alive. Other survivors of late abortion are reported (Adhikari, 1998; Kramer, 2004), though no long-term survivors have been delivered so prematurely. Of 185000 abortions carried out in England and Wales in 2002, over 3300 (1.8\%) were performed at 520 weeks' gestation. Almost $75 \%$ of abortions on UK residents done at 520 weeks' gestation were performed in private clinics (Department of Health, 2003). Beyond 20 weeks, accuracy of ultrasonic gestational age assessment is limited to+10 14 days. A fetus deemed to be $22+$ weeks may therefore be more mature than expected and viable.

The number of infants born alive following procured abortion in the UK is unknown; this information is not collected by the Department of Health in its detailed annual abortion statistics. There is no existing official mechanism by which to report such cases, and no apparent statutory requirement to do so. The failure rate for medical abortion in the first trimester is between 1 and 14 per 1000 (RCOG, 2004). The late mid-trimester failure rate with the drug combination used in this case is unknown. Advancing gestational age is believed to increase the risk for failure of medical abortion (Winikoff et al., 1996). For terminations at 522 weeks' gestation, intracardiac potassium chloride is a recommendation to ensure that a fetus is born dead (RCOG, 2001).

Late abortion raises serious practical, ethical, and professional concerns. The dilemma of being telephoned about an infant born showing signs of life following termination of pregnancy is one that many paediatricians have faced. If viable, and resuscitated in accordance with current guidelines (BAPM, 2000), those infants who survive may suffer significant morbidity. Their short and long term medical care entails enormous resource implications for local neonatal services ( $\mathrm{O}^{\prime} \mathrm{Neill}$ et al., 2000; Petrou et al., 2001). Conversely, private abortion clinics do not have the trained personnel or specialised equipment necessary to resuscitate viable infants, and may be more inclined to overlook signs of life. Inevitably, this raises the issue as to whether late abortions should be undertaken in private clinics.

The present case suggests a failure of crisis pregnancy counselling. Maternal ambivalence implies poor candidacy for elective second trimester abortion. Many women do change their minds about an initial abortion decision. A change of mind in favour of continued pregnancy is far commoner in second trimester abortion applicants compared to first trimester applicants. In a study of 1419 women who booked for abortion, overall almost $10 \%$ subsequently opted to continue pregnancy to term. However, among applicants of 518 weeks gestation, $75 \%(15 / 20)$ decided to continue pregnancy (So" derberg et al., 1997). Unlike surgical abortion, medical abortion is a process lasting from days to several weeks.

A change of mind in late mid-trimester, either after an initial abortifacient drug dose or after drug failure, has at stake the potential birth of a viable infant and all the attendant stresses and complications of prematurity. Second trimester abortion is also associated with increased mortality and morbidity (Gans Epner et al., 1998; Department of Health, 2003). Adequate exploration of ambivalence is therefore especially pertinent in late abortion counselling. Current guidelines for care of women requesting abortion list failure to terminate and on-going pregnancy as recognised complications (RCOG, 2004). Counselling should also mention the possibility of delivering a viable live born infant following failed late abortion, and that surviving infants may suffer significant impairments as a result of premature delivery. 


\section{References}

Adhikari M. (1998) Caring for babies who survive an abortion attempt - an ethical dilemma. South African Medical Journal, 88,578.

British Association of Perinatal Medicine (2000) Fetuses and newborn infants at the threshold of viability: a framework for practice. London, BAPM. Available from:

http://www.bapm.org/documents/publications/threshold.pdf [Accessed 25 ${ }^{\text {th }}$ November, 2004].

Department of Health (2003) Abortion statistics, England and Wales: 2002. Bulletin 2003/23. London, HMSO. Available from: http://www.dh.gov.uk/assetRoot/04/06/98/27/04069827.pdf [Accessed 25th November, 2004].

Gans Epner J.E., Jonas H.S. and Seckinger D.L. (1998) Late-term abortion. The Journal of the American Medical Association, 280,724-729.

Kramer S. The Survivors of Abortion [homepage on the Internet]. URL:

http://members.tripod.com/*joseromia/survivors.html [Accessed 25th November, 2004].

O'Neill C., Malek M., Mugford M., Normand C., Tarnow-Mordi W.O., Hey E. and Halliday H.L. (2000) A cost analysis of neonatal care in the UK: results from a multicentre study. ECSURF Study Group. Journal of Public Health Medicine, 22,108 - 115.

Petrou S., Sach T. and Davidson L. (2001) The long-term costs of preterm birth and low birth weight: results of a systematic review. Child: Care, Health and Development, 27, 97-115.

Royal College of Obstetricians and Gynaecologists (2004) The care of women requesting induced abortion. (Evidence-based Guideline No. 7). London, RCOG. Available from:

http://www.rcog.org.uk/resources/Public/induced abortionfull.pdf [Accessed 25th November, 2004].

Royal College of Obstetricians and Gynaecologists (2001) Further issues relating to late abortion, fetal viability and registration of births and deaths. London, RCOG. Available from:

http://www.rcog.org.uk/mainpages.asp?PagelD $=768$ [Accessed $25^{\text {th }}$ November, 2004].

Söderberg H., Andersson C., Janzon L. and Sjo“berg N.O. (1997) Continued pregnancy among abortion applications. A study of women having a change of mind. Acta Obstetrica et Gynecologica Scandinavica, 76, $942-947$.

Winikoff B., Ellertson C. and Clark S. (1996) Analysis of failure in medical abortion. Contraception, 54, $323-327$.

Competing interests

None of the authors has any competing interest to declare.

Correspondence to: Paul Clarke, Neonatal Intensive Care Unit, Hope Hospital, Salford, M6 8HD, UK. Tel. 0161 206 5276/8; Fax:0161 206 5786; E-mail: drpaulclarke@hotmail.com 